\title{
Green University: the Important Influencing Factor of Regional Development
}

\author{
Jun $T u^{1,2, a}$ \\ ${ }^{1}$ School of Management, Wuhan Textile University, Wuhan 430073, P.R.China \\ ${ }^{2}$ Research Center of Enterprise Decision Support, Wuhan Textile University, Wuhan 430073, \\ P.R.China \\ atujun_cn@yeah.net
}

\section{Keywords: Green University, Regional Development, Driving Force}

\begin{abstract}
Green university construction not only has practical significance to the Regional development, but also has far-reaching educational significance to the ecological civilization. Firstly, with the basic elements of regional development, a brief path analysis of regional development using a relevant theory of economic growth and regional economy will be done. Secondly, the new driving force of regional development is summarized based on the present situation of China regional economic development. Thirdly, the relation between driving force of regional development and the green university must be analyzed. On this basis, this paper built a basic transmission mechanism form green university to regional development.
\end{abstract}

\section{Introduction}

Regional economic gathering shows a high concentration of population, industries on specific geospatial carrier. And from the economic point of view, regional economic gathering means high concentrated population and high economic density in a certain area. In China, the economic density high value areas are mainly located in the coastal zone, as well as the central region. Among them, there are five top industry gathering areas in the eastern coast: the Bohai Rim, the Yangtze River Delta, Pearl River Delta, the Liaodong Peninsula and the west side of industrial gathering areas. Two major industrial gathering areas are located in the central region: Changzhutan and Wuhan industrial gathering areas. In addition, three major industrial gathering areas are in the western region: Chengyu, Central Shanxi plain and northern slope of Tianshan Mountains industrial gathering areas.

The urbanization of the area is an important symbol to measure a national and regional socio-degree of organization and management level, and to measure a national and regional economic, social, cultural, scientific and technological level. The Urbanization means that a large number of rural population moves into the cities, urban residents' income level rises continuously, and market expands and attracts more and more investors continuously. With the accelerated pace of industrialization, the level of urbanization in China continues to increase. By the end of 2017, the total urban population of mainland in China has been up to $813,470,000$, accounting for $58.52 \%$ of the country's total population; and the level of urbanization has been $6.95 \%$ higher than that in 2011 .

China's regional economic development has demonstrated some positive effects such as gathering and urbanization, but the negative effect in the development process can't be ignored either. The serious imbalance of regional economic development in China is mainly shown in the following aspects: the economic development gap between coastal and interior areas, the economic development gap among the eastern and central-western areas, the economic development gap among different provinces, the economic development gap between the northern and the southern areas, and the economic development gap between urban and rural areas. It is urgent to study the development direction and driving force of China's regional economic development. 


\section{Development path and driving force of regional development}

\subsection{Traditional theory of regional economic development}

Generally regional economic development theory has four main theories: External Economic Theory, Gathering Economic Theory, "Center - Periphery" Theory and Growth Pole Theory. First of all, Marshall(1920) from the point of view of the external economics studied the emergency of industrial clusters, Weber(1929) from the perspective of gathering economics concept explained the phenomenon of industrial clusters, Krugman(1991,1995) through New Trade Theory studied the the principle of regional economic development. Peru(1945) did the research of industrial clusters in his Growth Pole Theory.

\subsubsection{External Economic Theory}

Marshall from the point of view of new classical economics through the research of industrial organizations concluded indirectly that enterprises gathering resulted from the pursuit of external scale economy. Marshall also explained the phenomenon of industrial clusters by industrial scale expansion resulting in the increase of knowledge and the dissemination of technical information. Economist Paul Krugman thought the three key elements of Marshall's industrial clusters theory were labor market sharing, the creation of specialized subsidiary industries and technology spillover. Marshall's theory does not consider the change of some dynamic factors, such as the enterprise's business growth in the region and the enterprise's immigration and emigration among regions.

\subsubsection{Gathering Economic Theory}

Weber (1929) is the founder of Industrial Location Theory; he was the first scholar to use gathering economy concept, and he clarified that whether enterprises gathered depended on the benefit of gathering and the contrast of the cost. Weber believed that industrial gathering could be divided into two stages: in stage 1, gathering advantage came from the expansion of the enterprises themselves, which is the lower stage of the industry gathering; in stage 2, industrial gathering came from interrelated organization among enterprises, which is the important advanced gathering stage. Webber explored the factors that produced industrial gathering advantages, and quantified the gathering form rules. But Weber's research ignored all systematical, social, cultural, and historical factors, focused on resources and energy simply. In the actual economic life, to a considerable extent the form of industrial gathering depends on regional social and cultural factors.

Krugman (1991) in his book "Increasing Returns and Economic Geography" applied a simple model to explain that a country or region realized the scale economy through minimized transportation costs, so manufacturing firms tended to make location choice in greater demand market. Krugman combined trade theory with location theory, revealed the industrial gathering mechanism in a deep level through rigorous mathematical modeling method, and made up the insufficient view of Marshall and Weber. But Krugman ignored non-material contact (such as information, technical contact) and informal contact (inter personal trust-based contact)emerged in enterprise activities.

French economist Peru first proposed the concept of growth poles when studying the non-equilibrium growth theory in 1950. He thought the enterprises dispersed geographically, and formed forces boundary of their own. According to Peru, the economic space, existing among the factors, being different from geographic space in general sense, focuses on economic ties, the dominant sector and the enterprises of high innovation capacity.

\subsection{Driving force of regional economic development}

\subsubsection{Economy of scope}

The development of modern science and technology promotes the high integration of industrialization and information, and makes development space of the scale economy relatively small. The scarcity of natural resources, ecological damage to the environment, policy changed in development mode and the global carbon reduction common action make the improvement of economic quality and efficiency become the inevitable choice for sustainable economic development. 
It is not difficult to determine, for regional economic development, the era of focusing on economy of scale and pursuing quantity-oriented growth has nearly ended, and the era of pursuing quality or efficiency oriented growth guided by economy of scope has already began. The economy will become one of the driving forces in the future regional economic development.

\subsubsection{Knowledge and innovation}

In the era of knowledge economy, the economy, taking the high-tech industry as the core, built on the production, distribution, use, and consumption of the knowledge and information will become dominant. After Knowledge becomes a resource even the first resource of the region, regional economic growth mode will change fundamentally. The establishment of a network of high-speed information as well as the large amount of information makes the regional economic regulation built on a timely, accurate, fast, and scientific basis, and makes it change from "periodicity "of the traditional regional economic development to "persistency" of knowledge economy era .

\subsubsection{Culture}

The regional culture is the important competitiveness of regional development. The Regional Culture is the sum of the factors of a sense of community, value, mental outlook, behavior patterns and management style of the region. On one hand, regional culture constantly changes and is gradually enriched often with the development; on the other hand, the culture is relatively stable, is often handed pass through generations, and always maintains some unique quality which different from the quality in other areas. The resource capital can be got through transactions and circulation in the process of economic globalization, but the spirit literacy, value pursuit and institutional system can't be easily displaced and transferred. So the culture has become the regional nonviable source and core competitiveness.

\subsubsection{Network urbanization}

Information technology, globalization and network not only gives birth to a new paradigm of social and economic development, but also affects the regional economic patterns, and finally makes the urban and regional spatial development model change fundamentally and show a new feature. In the process of urban expansion from the center to the edge, regional ties have been increasing gradually, and regionalization degree has been strengthening. For example, both "Beijing City Master Plan (2004-2020)" and "Tianjin City Master Plan (2005-2020)" have clearly identified city domain space layout structure.

\subsubsection{Sustainable development}

There are also the reality of population growth, resource scarcity and environmental degradation in regional development. Global environmental problems have posed a great threat to human survival and development. In 1992, the unprecedented scale of the assembly of Heads of the United Nations Environment and Development held in Rio de Janeiro, Brazil, which made sustainable development be as a goal of all the countries all over the world. Under the resource constraints and environmental friendly conditions, the establishment of regional sustainable development index system that meeting the requirements of a new era provides a scientific basis for the regional development policies and countermeasures.

Traditional regional economic development path and its influencing factors can be summarized as follows: the function of location factors in the formation of regional economic pattern; the role of institutional factors in the regional economy structure; regional development differences resulting from policies oblique effect; regional development differences caused by the human resource endowments. With the improvement of the level of economic and social development, human resources conditions will play an increasingly important role in regional economic development. Although under the market-oriented condition, the inter-district flow of resources and elements becomes easier and easier, the higher education in the region has been influencing the regional development greatly and continuously. 


\section{The relation between driving force of regional development and the green University}

In 2006 the report "Leadership Test: the Future of American Higher Education Report" issued by the United States proposed: Today we can claim without exaggeration that higher education has become one of the greatest achievements in the United States. Higher education has been playing an unprecedentedly important role in the knowledgeable and economic society. It is the main birthplace of human capital and intellectual capital which are necessary for improving labor quality and growth, and it's the main way to promote social harmony and to promote the rational flow of society.

The main function of university research is personnel training, especially the training of personnel engaged in scientific research. At the university, a large number of personnel receive specialized training and grasp the new ideas, new theories, new technologies and new processes. With the knowledge they obtained at the university, the personnel above bring energy to the economic society. The staff in the government and the enterprises enters the university for personnel retraining and corporate laboratories are built at the university. The other way round, the demand of the government, the society and the enterprises affects the innovation activities of the university, which drives the reform of the university's internal mechanism and makes the university serve the government, the society and the enterprises more effectively.

After "Earth Summit" in 1992, it's imperative to build green campus, implement green education and cultivate green talent at the university. U.S. Green Building Council (USGBC) defined green campus as: A higher education community that is improving energy enhancing efficiency, conserving resources, and enhancing environmental quality by educating for sustainability and creating healthy living and learning environments.

There are all sorts of contacts between green university construction and regional economic and social development. The development of regional green campus leads and guides regional economic and social development. In this relationship, the development of regional green university is not only the driving force but also the sign of the regional economic and social development. This relationship is built on the condition that both the university construction and the economic and social development have entered a new stage of the times when the university focuses on green campus and the regional development depends on new driving force. In this new stage, the regional economic and social development no longer relies mainly on natural resources or capital, or on the general labor force, low-level technical personnel or other primary factors of production, but relies mainly on high-quality innovative talents and other external environment. In the region green university affects regional development in personnel training, scientific and technological innovation and social services. The transmission mechanism of green university promoting regional development as is shown in figure 1.

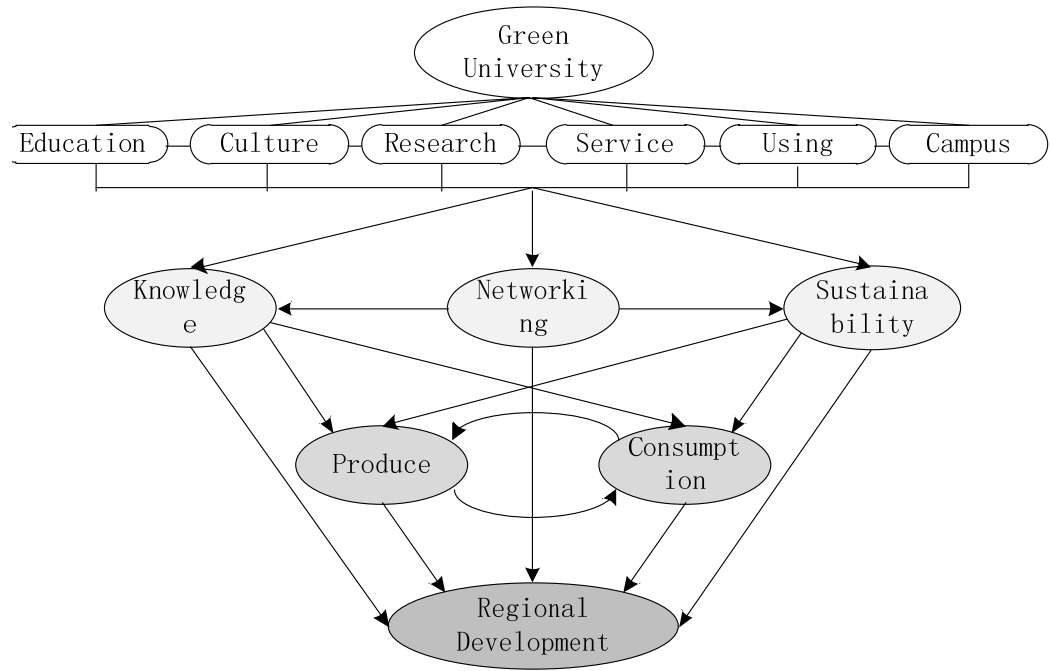

Fig. 1. This shows a figure consisting of transmission paths form green university to regional development 


\subsection{Producing knowledge and promoting knowledge spillover directly}

Famous American thinker, former Harvard University president Derek Bok thought that $t$ the University was designed to perform a special mission- discovering and delivering knowledge. University research has made a significant contribution to the development of treasure house of human knowledge. The exploration of truth, the creativity and the innovation are the basic functions of the University. In addition, a modern society is a learning society in which knowledge and cultural production must rely on the heavy accumulation of the university. University will become the knowledge center in the learning society. Industries in the new century will rely on the production of knowledge more and more. With its own advantages, university stands in the center of society in the provision of new knowledge, the dissemination of new technology (Anders, 2010) and the training of innovative talents (Manuel, 2009) and comprehensively promotes the social, political, economic and cultural development.

\subsection{Creating innovation directly and indirectly}

University produces technological innovation, knowledge innovation, product innovation, management innovation directly and generates business model innovation, social and economic innovation indirectly. Regional competitiveness and university spillovers are strong complements in fostering innovation activity of entrepreneurial firms (David, 2012). In fact, creativity as an economic form has risen to the level of national policy (Hesmondhalgh, 2007). University has its unique advantages in innovation. The green technology, green projects, green products in the green university can improve the efficiency and quality of the innovation. The construction of green university will change people's old philosophy, consumption patterns, and lifestyle, generate new business models and new management pattern simultaneously and promote regional to develop toward a new mode and direction.

\subsection{Parsing and disseminating culture}

The University is always nation-oriented, future-oriented and world-oriented. University creates the ideological and theoretical, scientific and technological achievements and other cultural achievements which play a guiding role in the cultural development of society. University absorbs cultural nutrients from the society and converts the forward-looking and advanced the concept to the society simultaneously. The scientific spirit, the cultural traditions, the sense of innovation and the elegant entertainment form in the university culture radiate and affect the society, lead social and cultural development to a higher level, and add new content and nutrients for the progress and development of the society and culture. The concept of green culture and sustainable development widespread in the construction of green university, which probably change people's lives fundamentally.

\subsection{Being important part of the creative economy and urban network}

Two main external conditions of creative economy are: close to a comprehensive university; belong to worldwide metropolitan areas (Florida, 2005). In the post-industrial era, the University is playing an increasingly important role in the growth of the creative economy for the city or region, such as Stanford for Silicon Valley, Harvard and Massachusetts for traditional Route 128 and emerging biotechnology cluster. In these two classical cases, the university's role in regional economic growth is strong and direct. In China, the ongoing green campus construction in some universities also reflects the coordination with regional development. Tongji University and the region where it is located make core development concept together -"Joint Development of Three Areas- university campuses, technology parks and public community". Siping Road Campus of Tongji University and the region it belongs to build "around Tongji knowledge and economy circle" together. The creative economy is often green economy. Green university strengthens the qualities which makes the innovation and the development more competitive. 


\subsection{Being exemplary community in the sustainable development of resource constraints and friendly environment}

University campus tends to develop to University City. University City has actually turned into a special community which has radiation effects on its surrounding areas in knowledge, culture, technology, environment and lifestyle. Green university will be classical demonstration community in green environmental protection, green management and green economy based on the widespread use of green building technology, and the new generation of energy-saving technologies. The construction of green campus can also provide some reference in solving the unhealthy urban and regional development problems caused by lack of bearing capability and adaptability in resources, environment, economic base, social conditions and many other aspects (Antje, 2012).

\section{Summary}

Through the path to the regional development, direction and driving force, the relationship between green university and regional development driving force is explored. The university is the power source for the development of regional innovation, whose functions are providing innovative entrepreneurial talent, technology, projects and intellectual support for regional economic and social development, promoting the development of ecological civilization. Technology park is a key to regional innovation development, a growth pole of regional economic development, an important base for a combination of industries, universities and researches and an innovation place for university teachers students and researchers. Public community provides public services for the university campus and technology park, and creates a social and ecological environment suitable for the settling down and communication.

\section{Acknowledgement}

This research was financially supported by the Soft Science Project of Science and Technology Department, Hubei Province (Grant NO.2017ADC102), Humanities and Social Sciences Project of Education Department, Hubei Province (Grant NO.16AGL024).

\section{References}

[1] Hesmondhalgh, David. The Cultural Industries [M].London: Sage, 2007:146.

[2] Anders B. Working with distant researchers distance and content in university-industry interaction [J]. Research Policy, 2010, (39):1311-1320.

[3] Manuel A, Daniel C, Esther F. University spillovers and new business location in high-technology sectors: Spanish evidence [J]. Small Bus Econ, 2009, (36):365-376.

[4] David B, Audretsch M H, Erik E L. Regional competitiveness, university spillovers and entrepreneurial activity [J]. Small Bus Econ, 2012, (39):587-601.

[5] Florida R. Cities and The Creative Class [M].New York, NY:Rout ledge, 2005:252.

[6] Antje D. Environmental Management Systems (EMS) implementation processes and practices in European higher education institutions Top-down versus participatory approaches [J]. Journal of Cleaner Production, 2012, (31):81-90.

[7] L P Fu, Jun T. University research to the enterprise technology innovation of spatial knowledge spillovers under the perspective of technology transfer [J]. Journal of management research and development, 2015, 27 (2):34 -46. 